\title{
Políticas públicas para a leitura e a literatura: o legado autoritário e a influência do mercado
}

Victor Hugo Adler Pereira ${ }^{1}$ Mirna Aragão de Medeiros ${ }^{2}$

$\mathrm{O}$ acesso à leitura, assim como à escolaridade, teve tratamento político no Brasil desde os primeiros instrumentos de ordenamento jurídico para a construção de um país independente de Portugal. A Constituição de 1824 proclamava o direito de frequentar escolas para todos os cidadãos. No entanto, o efetivo exercício desse direito tornavase difícil para os escravos, já que essa mesma carta constitucional restringia a qualificação como cidadão, excluindo os escravos e seus descendentes (Reis, 2005, p. 1). Tais empecilhos ficaram mais claros quando a Resolução Imperial $n^{\circ} 1.854$ proibiu os escravos de frequentar escolas. Relacionados a essas restrições, apontavam-se os baixos índices de alfabetização entre negros escravos e forros em uma avaliação divulgada em 1872 que registrava "um escravo alfabetizado para 999 analfabetos e de 0,6 mulheres escravas para 999,4 analfabetas" (Moysés, 1994, p. 200 apud Reis, 2005, p.1). Nesse sentido, observem-se as tabelas a seguir, que oferecem um balanço estatístico do Império.

TABELA 1 - Evolução populacional

(Em milhões)

\begin{tabular}{lccc}
\hline Ano & 1819 & 1872 & 1890 \\
\hline População & 4,6 & 9,9 & 14,3 \\
\hline
\end{tabular}

Fonte: Alvito (2014, p. 3).

TABELA 2 - Províncias mais povoadas (1872)

(Em milhões)

\begin{tabular}{llc}
\hline & \multicolumn{1}{c}{ Província } & População \\
\hline $1^{\mathrm{o}}$ & Minas Gerais & 2,1 \\
$2^{\mathrm{o}}$ & Bahia & 1,38 \\
$3^{\mathrm{o}}$ & Pernambuco e São Paulo & 0,84 \\
\hline
\end{tabular}

Fonte: Alvito (2014, p. 3).

\footnotetext{
${ }^{1}$ Professor da Universidade do Estado do Rio de Janeiro (UERJ), Rio de Janeiro, RJ, Brasil. Pesquisador bolsista apoiado pelo CNPq e pelo Programa Prociência/UERJ-Faperj. E-mail: vhap@uol.com.br

${ }^{2}$ Doutoranda em história na Universidade Federal do Estado do Rio de Janeiro (Unirio), Rio de Janeiro, RJ, Brasil. E-mail: mirna.arag@gmail.com
} 
TABELA 3 - Composição por grupos de cor

$($ Em \%)

\begin{tabular}{lll}
\hline \multicolumn{1}{c}{ Ano } & 1872 & 1890 \\
\hline Branca & 38,0 & 44,0 \\
Parda & 41,4 & 42,0 \\
Preta & 20,0 & 14,6 \\
Amarela e s/d* & n.d. & n.d. \\
\hline
\end{tabular}

Nota: * Somente a partir do censo de 1940.

Fonte: Alvito (2014, p. 3).

TABELA 4 - Índice de analfabetismo (1872)*

$(\mathrm{Em} \%)$

Entre os escravos

99,9

População livre

80,0

Somente mulheres livres

86,0

Nota: * Apenas 16 \% da população entre 6-15 anos frequentava escolas e havia somente 12 mil estudantes secundários.

Fonte: Alvito (2014, p. 3).

Esses dados devem ser avaliados diante de duas circunstâncias. A primeira delas é o fato de os índices de alfabetização serem também bastante baixos entre a população de alforriados e brancos. A segunda é que, mesmo a utilização da língua escrita poderia estar submetida a limitações, como a restrição de seu uso a finalidades práticas imediatas e a material para memorização, substituindo a predominante cultura oral. Esse aspecto do problema relaciona-se a um comentário preconceituoso de Gustave Le Bon:

Sem dúvida a instrução permite, graças à memória que possuem os seres inferiores e que não é absolutamente privilégio do Homem, dar ao indivíduo colocado no lugar bem abaixo da escala humana o conjunto de noções que possui um europeu. Se faz facilmente de um negro bacharel e advogado, mas só aplicamos um verniz muito superficial e ineficaz sobre sua constituição mental (Le Bon apud Souza, 1998, p. 92).

O mero acesso à alfabetização, no entanto, constituiu-se numa questão política de consequências amplas, desde o século XIX, graças a uma medida governamental que continuaria em vigor até a promulgação da Constituição de 1988: a proibição do voto do analfabeto. As pressões da transformação imposta pelo 
desenvolvimento econômico entravam em contradição com as restrições à alfabetização do maior contingente de mão de obra, a população negra. E a proximidade da abolição da escravatura, que se anunciava nas últimas décadas do século XIX, motivou o crescimento das ações para oferecer um mínimo de formação educacional aos escravos em algumas regiões do país. Como exemplo dessas ações, registra-se a participação do Conde José Vicente de Azevedo em várias iniciativas educacionais ligadas à Igreja Católica, algumas delas afetando diretamente a população negra, como a criação do Educandário Sagrada Família, em 1990, além do projeto para educação de meninas negras, retomado em 1903 e que, a partir de 1918, funcionaria desdobrado no Orfanato Santa Zita e no Colégio Sagrada Família (Souza e Hilsdorf, 2000, p. 10).

Já nos anos 1930, diante de um surto de modernização do país, revelava-se a influência da perspectiva de que não bastava a alfabetização, encarada como domínio da técnica da escrita, para implementar esse projeto: era necessário estimular práticas de leitura mais complexas. Relaciona-se essa perspectiva à atual concepção de letramento. Na Inglaterra e nos Estados Unidos, criavam-se bibliotecas públicas e gratuitas já desde o século XIX, expandindo-se pela Europa continental. Em 1862, o governo francês decidiu que "cada escola seria dotada de uma biblioteca escolar. Ao mesmo tempo, os movimentos democráticos, conscientes da importância da leitura para o triunfo de suas ideias, abriram em toda parte bibliotecas populares" (Perrotti, 1999, p. 130).

Embora essa medida aponte para o reconhecimento de que o ensino nos programas escolares era insuficiente para suprir as necessidades impostas pelas transformações econômicas e sociais, a utilização efetiva das bibliotecas passou até meados do século XX, nesses países, por variações, tanto na procura pelo público, quanto no investimento e manutenção pelos governos. Essa variação não afetava o consumo de jornais e da literatura imediatamente para o mercado do entretenimento, mas continuou em relação à literatura e à leitura de textos de maior complexidade até haver maior desenvolvimento das forças produtivas e da educação formal (Perrotti, 1999, p. 131). A expansão da leitura, portanto, está diretamente relacionada ao desenvolvimento econômico e social, o que se comprova, pelo modo com que ocorreu no Reino Unido e nos Estados Unidos, centros avançados do capitalismo, em contraste com outros países ocidentais. 
No Brasil, a ação do Estado, de modo mais contínuo e eficiente, até 1935, pode ser observada principalmente no aprimoramento, em diversos sentidos, da educação formal na rede pública de ensino. A partir dos anos 1930, o regime de Vargas assumiu a promoção da cultura como um negócio de Estado, instituindo mecanismos de estímulo e controle das atividades das diferentes modalidades e "níveis" da produção cultural (Pereira, 1998, p. 41-42). O ministro Gustavo Capanema foi responsável por várias medidas que demonstravam a preocupação do governo com as questões relativas à leitura no país, criando o Instituto Nacional do Livro (INL), através do Decreto-Lei $n^{\circ}$ 93, de 21 de setembro de 1937. Suas atribuições foram: a edição de obras literárias julgadas de interesse para a formação cultural da população, a elaboração de uma enciclopédia e de um dicionário nacionais e a expansão, por todo o território nacional, do número de bibliotecas públicas. Alguns intelectuais destacados, como Augusto Meyer, Sergio Buarque de Holanda e Mario de Andrade, estiveram à frente do INL durante o Estado Novo, mas não deram conta de todas as propostas iniciais para a instituição, priorizando a expansão das bibliotecas públicas:

Até 1945 não foram concluídos nem o dicionário nem a enciclopédia brasileira, mas o número de bibliotecas públicas, principalmente nos estados menos prósperos do país, cresceu muito graças ao apoio do INL, que as auxiliava na dispendiosa tarefa de constituição de acervo e capacitação técnica (CPDOC, 2015, s.p.).

Mario de Andrade iniciou o movimento de criação de bibliotecas públicas populares, em sua passagem pelo Departamento de Cultura do Município de São Paulo, e, em artigo de 1939, justifica a importância dessa iniciativa para o país:

A criação de bibliotecas públicas populares me parece uma das atividades mais atualmente necessárias para o desenvolvimento da cultura brasileira. Não que essas bibliotecas venham resolver qualquer dos dolorosos problemas da nossa cultura, o da alfabetização, o da criação de professores do ensino secundário, por exemplo. Mas a disseminação, no povo, do hábito de ler, se bem orientada, criará fatalmente uma população urbana mais esclarecida, mais capaz de vontade própria, menos indiferente à vida nacional. Será talvez um passo agigantado para a estabilização de uma entidade racial que, coitada, se acha tão desprovida de outras forças de unificação (Andrade apud Perrotti, 1999, p. 138-139). 
No texto acima, Mario de Andrade supervaloriza o poder da leitura na superação das dificuldades para o "desenvolvimento da cultura brasileira". O destaque concedido a esse tópico relacionava-se à crescente importância, desde os anos 1930, das discussões em torno da cultura brasileira e da consciência nacional, entre intelectuais de diferentes posições políticas e matizes ideológicos (Mota, 1994, p. 54). Revelava uma perspectiva comum entre muitos intelectuais nesse período e que se manteve nas décadas subsequentes, de que o acesso comum a determinados bens culturais poderia contribuir para a unificação nacional. Desse modo, os intelectuais, movidos pela filantropia ou afinados com propostas populistas, sentiam-se no direito e obrigação de decidir a que bens culturais as classes populares deveriam ter acesso e de contribuir para que fossem "distribuídos" através de medidas de políticas públicas.

No entanto, observa Edmir Perrotti que "o distributivismo cultural, seja em sua versão filantrópica, seja na versão populista, não conseguiu fazer face à realidade de um país como o Brasil" (Perrotti, 1999, p. 140). O sistema educacional reproduzia os abismos sociais que remontavam à escravidão, perpetuando os contrastes e as desigualdades entre educandos e educadores de diferentes níveis de renda, que se refletiam nos espaços destinados à educação e à cultura, dificultando a difusão da leitura. Perrotti, em 1999, observava que: “As escolas continuam sem bibliotecas e a biblioteca pública segue sendo apêndice escolar, fornecedora de material de pesquisa" (Perrotti, 1999, p. 140).

A enorme distância entre a escola e a vida cotidiana persiste até a atualidade como um problema que provoca o abandono da escola pelos alunos das classes populares ainda nos primeiros anos. Além disso, torna o conhecimento um instrumento da manutenção da sujeição dos indivíduos à hierarquia social.

Nos anos 1960, num contexto em que se fazia a crítica das causas históricas do subdesenvolvimento brasileiro, Paulo Freire avaliou as implicações políticas do ato da leitura e situou problemas relacionados ao modo com que vinha sendo tratada historicamente a educação escolar no país. Dedicando-se à alfabetização de adultos, procurou fazer do processo de descoberta da leitura uma abertura para a compreensão da inserção dos indivíduos no contexto histórico-social. Considerava que a prática educativa devia partir de uma experiência dialógica: “Como educador, preciso ir 'lendo' cada vez melhor a leitura do mundo 
que os grupos populares com quem trabalho fazem de seu contexto imediato e do maior, de que o seu é parte" (Freire apud Souza, 2001, p. 124). Continuando seu raciocínio, o educador deixa claras as diferenças na conceituação de leitura:

O que quero dizer é o seguinte: não posso de maneira alguma, nas minhas relações político-pedagógicas com os grupos populares, desconsiderar seu saber de experiência feito. Sua explicação do mundo de que faz parte a compreensão de sua própria presença no mundo. E isso tudo vem explicitado ou sugerido ou escondido no que chamo "leitura do mundo" que precede a leitura da palavra (Freire, 2000. p. 83 apud Souza, 2001, p. 124).

Freire partia do reconhecimento da distância ou da hierarquia que se estabelece entre o mundo da escrita e o universo simbólico dos educandos, pela inexistência do diálogo dos instrumentos de conhecimento com a bagagem de suas experiências e as formas de conhecimento existentes em fontes não escolares. Considera que essa desvinculação faz com que a criança, o jovem ou o adulto, em alguns meios sociais, não identifiquem a leitura como uma ferramenta de compreensão do mundo e, levados por procedimentos pedagógicos que são aplicados desde a alfabetização, distanciam-se de um universo que parece reservado a parcelas privilegiadas da população. $\mathrm{O}$ educando, passaria, então, a utilizar a capacidade limitada de decifrar os signos da escrita a textos reduzidos, destinando essa modalidade da língua a finalidades práticas, conformandose a situações de exclusão e à posição subalterna.

O método de alfabetização de Paulo Freire surgiu junto às atividades promovidas pelo Movimento de Cultura Popular (MCP), criado em maio de 1960 junto à Prefeitura de Recife, com o apoio do governador de Pernambuco, Miguel Arraes. O pedagogo era Diretor da Divisão de Pesquisa e Coordenador do Projeto de Educação de Adultos do MCP. Os chamados "círculos de cultura" realizavam-se como uma ocasião de diálogo entre os sujeitos envolvidos no processo de alfabetização: educadores e trabalhadores que procuravam os núcleos do MCP (Uchoa apud Mota, 1994, p. 213). Esse método pressupunha a distinção entre a habilitação dos indivíduos a utilizar a língua para atividades práticas, adestrando-os ao manejo desta como técnica de comunicação, da possibilidade de o sujeito estabelecer relações mais complexas no âmbito das mensagens escritas e com o meio em que se insere, $\mathrm{o}$ letramento (Tfouni, 1995, p. 20). A alfabetização de adultos era 
estratégica na época para garantir a participação política das classes populares, já que o voto era vetado aos analfabetos, impedimento justificado como de "censo literário" na elaboração da constituição republicana de 1891, que acabou com o "censo econômico" (Ferraro e Kreidlog, 2004, p. 184-185). Vale lembrar que somente a Constituição de 1988 viria a permitir o voto dos analfabetos.

O método Paulo Freire foi aplicado em grande parte de iniciativas de alfabetização ligadas a grupos de promoção da cultura popular que, no biênio 1963/1964, proliferaram de norte a sul do país (Uchoa, 1965 apud Mota, 1994, p. 214-215). Essas iniciativas foram proibidas ou perseguidas com a implantação da ditadura civil-militar em 1964, consideradas arma de propaganda do governo deposto ou focos de subversão. Foi criado, através de decreto governamental de 1967, o Movimento Brasileiro de Alfabetização (Mobral), procurando substituir os trabalhos de alfabetização que vinham sendo realizados junto às classes populares em todo o país por diferentes grupos. A implantação do Mobral foi gradativa, dependendo dos recursos financeiros e da organização dada pelo governo federal, com a participação dos governos locais. Quanto à orientação metodológica, apesar de ter como ponto de partida as experiências dos educandos, tinha como meta prioritária prepará-los para sua inserção no mundo da produção, sem desenvolver a consciência crítica de suas relações com este. Funcionava, portanto, como um instrumento para formação de mão de obra para o projeto de desenvolvimento do regime, atendendo nas cidades às circunstâncias impostas pelo grande êxodo rural.

À proibição da continuidade de experiências na área da educação e cultura voltadas para as classes populares acrescentaram-se as limitações impostas à circulação de informação pela censura, desde o golpe de 1964, e, com maior rigor, a partir da promulgação do Ato Institucional $n^{\circ} 5$, em 1968, para dificultar a produção e difusão de bens culturais ou evitar que ela se tornasse fonte de pensamento crítico capaz de contestar o regime. No entanto, ainda durante a ditadura, em debate sobre a crise da indústria editorial, Mário Fittipaldi, presidente da Câmara Brasileira do Livro, afirmou que houve o crescimento da indústria editorial, decorrente do "milagre econômico", caracterizando as particularidades desse fenômeno:

Existem em nosso país duas crises do livro e não uma crise apenas. A mais visível, que nos afeta no momento, é a crise que está afetando a 
economia do país. Seria ingênuo supor que um país afetado em sua contextura econômica pela crise que nós conhecemos, tivesse uma indústria do livro imune. Vamos dar a essa crise o nome de crise sazonal, perfeitamente superável. [...] Mas há um outro tipo de crise na indústria do livro, que é o que poderíamos chamar de crise estrutural. Temos uma produção atual de 240 milhões de livros, o que dá uma relação de dois livros anuais por habitante. Mas, desses 240 milhões, nós temos que deduzir, do volume físico da produção, quase $70 \%$ de livros didáticos nos três níveis [...]. Há uma outra produção muito grande de literatura de consumo, de coleções de crediário cujo volume físico é muito grande, que são vendidos de porta a porta. De sorte que o livro que nos interessa, para essa discussão, que o livro que vai para a livraria - ficção e não ficção deve estar resumido a entre 15 e $20 \%$ deste total de produção (Fittipaldi apud Melo, 1999, p. 82).

Discutindo essa declaração de Mário Fittipaldi, José Marques de Melo avalia que os limites à participação política impostos ao cidadão com condições financeiras de comprar livros não o estimulava a "fazer da leitura um instrumento de educação permanente e de reflexão social" (Melo, 1999, p. 83).

Durante o período ditatorial, aprofundaram-se os problemas endêmicos na educação e na cultura do país, com a expansão dos meios de comunicação e da indústria do entretenimento, comprometida direta ou indiretamente com a defesa e divulgação do ideário do regime. Essas circunstâncias influíam na produção de livros, afetando, sobretudo, a divulgação de obras literárias, conforme observou Silviano Santiago:

O objeto livro de ficção (como, aliás, o objeto livro em geral) circula de maneira limitada, deficitária e claudicante, numa média de 3 mil exemplares (cada edição) num país de 110 milhões de habitantes, segundo as últimas estatísticas. No melhor dos casos, 12 a 15 mil cópias (quatro ou cinco edições sucessivas) circulam pelo país no correr de quinze anos, sendo que o total de leitores do romance pode ser calculado na base otimista de 50 a 60 mil (Santiago, 1982, p. 25).

E acrescentou a esse quadro pessimista a avaliação de influentes estudiosos que apontavam para o aprofundamento do problema no transcorrer daquela década de grande controle das manifestações culturais e de expansão da televisão no país: 
A proporção de 60 mil leitores para 110 milhões de habitantes, já levantada por Roberto Schwarz em 1970 e retomada por Carlos Guilherme Motta em 1977, é ridícula e deprimente, mas é por essa inevitável assimetria que começaremos a nossa meditação pouco ortodoxa sobre o conhecimento que o objeto livro de ficção tem trazido para os habitantes deste país chamado Brasil (Santiago, 1982, p. 25).

Nesse ensaio, Silviano Santiago argumentava que o restrito público leitor para a literatura e a dificuldade de profissionalização dos escritores, e também muitas vezes sua origem social, nas classes dirigentes, interferiam no modo com que as obras ficcionais abordavam os problemas do país. Um efeito perverso dessas condições de produção era o agravamento de uma tendência, na recepção dos bens culturais mais prestigiados, a se tornar meros sinais de distinção, conforme observou Pierre Bourdieu (2007). Naquele momento, Santiago considerava que

o livro é, pois, objeto de classe no Brasil e, incorporado a uma rica biblioteca particular e individual, é signo certo de status social. Como tal, dirige-se a uma determinada e mesma classe, esperando dela o seu aplauso e a sua significação mais profunda que é dada pela leitura, leitura que se torna um eco simpático de (auto) revelação e de (auto) reconhecimento (Santiago, 1982, p. 28).

Portanto, na avaliação de Santiago, a inexistência de um diálogo com as perspectivas e as experiências de diferentes classes sociais limitam a capacidade de análise do país na literatura brasileira e criam efeitos perversos como torná-la propensa a um uso exclusivo como fetiche cultural. A proposta inerente ao ensaio de Santiago de possibilitar um acesso mais abrangente à literatura não se enquadra na perspectiva distributivista: ao dar atenção aos usos sociais do livro e da leitura, suscita a consideração crítica sobre as repercussões para uma gama mais ampla de leitores dos diferentes rumos que pode tomar a criação literária. Em sua avaliação dos problemas que afetavam a vida cultural e a literatura brasileiras, no ensaio citado de 1982, o crítico considera a repercussão e o efeito de fatores como as escolhas no campo da linguagem e a posição adotada pelos escritores diante da realidade.

Os problemas que atingiam endemicamente a produção e a difusão cultural no país não cessaram com o fim da ditadura, ampliando abismos entre manifestações canônicas e gêneros artísticos consagrados 
tradicionalmente e aqueles consumidos cotidianamente pela maior parte da população, principalmente na televisão. Foi bem sucedida a expansão das redes de comunicação no país, estimulada pelo reconhecimento dos governantes da necessidade de legitimação da ditadura implantada no país. A televisão transformou-se "em um dos mais importantes veículos de difusão do apanágio doutrinário do regime militar", afirmando em sua programação "novos hábitos, valores e comportamentos compatíveis com o tipo de sociedade e de relações sociais que se queria promover" (Wanderley, 2005, p. 75). A expansão dos meios de comunicação, durante o período ditatorial, teve relações com esse tipo de utilização, e interferiu nos hábitos de consumo cultural em grande escala no país. Contudo, estimulou a busca de alternativas ao predomínio de uma cultura voltada imediatamente para o mercado, provocando indagações sobre sua influência na ampliação do público leitor e em seu perfil (Melo, 1999, p. 84).

As avaliações sobre as dificuldades em ampliar o acesso à leitura redundaram, em 1991, numa iniciativa governamental: a criação do Programa Nacional de Incentivo à Leitura (Proler), em substituição ao Instituto Nacional do Livro, que existiu de 1937 até 1990. Outras iniciativas quanto a essa questão haviam se destacado nas décadas de 1980 e 1990, no âmbito governamental e através de parcerias públicas e privadas. Entre elas: a Ciranda de Livros, surgida em 1982, numa parceria da empresa Hoechst com a Fundação Roberto Marinho, que distribuía livros em escolas e realizava a formação de professores para divulgar a literatura infantil e juvenil; e o Projeto Leia Brasil, patrocinado pela Petrobras, que se baseava na criação de bibliotecas volantes instaladas em caminhões-baú.

O Proler foi organizado a partir de proposta da profa. Eliane Yunes, logo que Affonso Romano de Sant'Anna assumiu a direção da Biblioteca Nacional, e tinha como meta a criação de uma rede nacional de unidades promotoras das práticas leitoras (Coelho, 2009, p. 17). Um diferencial em relação a experiências anteriores foi o fato de que "as práticas de leitura, foram além do texto, exploraram múltiplas linguagens: pintura, cinema, dança etc." (Coelho, 2009, p. 26). A profa. Eliane Yunes coordenou o Projeto de 1991 até 1996, promovendo atividades que se propunham a ser uma renovação da "pedagogia dos atos de ler", baseadas em referências como a "sensibilização" dos leitores e a "desescolarização". Conforme a idealizadora do projeto, 
"não concentrar suas ações nas escolas era ato estratégico, uma forma de sensibilizar os profissionais da educação à medida que o projeto amadurecia" (Coelho, 2009, p. 28).

A estrutura do Proler e a orientação geral das atividades que promovia manteve-se até 1996, quando a equipe criadora foi desligada do programa. Até esta data, havia sido criada uma rede de $30 \mathrm{mil}$ colaboradores, que mobilizavam 300 municípios. Instituiu-se, a partir de então, uma "comissão coordenadora", que trouxe uma pluralidade de perspectivas, as quais passaram a conviver nas decisões sobre sua atuação (Coelho, 2009, p. 73).

No governo Fernando Henrique Cardoso (1985-2002), o ministro da Cultura Francisco Weffort avaliou que o norteamento da política cultural pelo incentivo fiscal não atraiu recursos suficientes para beneficiar a expansão do mercado livreiro e da leitura; por isso, apoiou diretamente o setor, dando continuidade a projetos anteriores e criando outros. Em sua gestão, o Proler passou a fazer parte do Programa Livro Aberto e incorporou uma diversidade de práticas de promoção da leitura.

Durante os dois mandatos de Luís Inácio Lula da Silva (2003-2010), o Proler teve diferentes coordenações e não foi um programa prioritário entre as várias iniciativas do Ministério da Cultura. No entanto, foram construídas muitas bibliotecas e elaborou-se o Plano Nacional do Livro e da Leitura (PNLL), como veremos adiante.

No âmbito das universidades, surgiram também, desde o fim da ditadura, propostas para torná-las mais atuantes junto a variados setores da sociedade. Por exemplo, o Ministério da Educação constituiu uma comissão, pela Portaria $n^{\circ} 66$ de 1993, com a participação, entre outras entidades de representação e quadros institucionais, do Fórum Nacional de Pró-Reitores das Universidades Públicas, propondo elaborar diretrizes políticas para o Programa de Extensão Universitária. ${ }^{3}$ Respondeu a essa mesma necessidade de fazer com que as universidades se aproximem das questões que afetavam o conjunto da sociedade a criação de instrumentos para enfrentar as deficiências relativas à leitura no país. Nesse contexto, deu-se a assinatura de um Termo de Cooperação firmado entre o Conselho de Reitores das Universidades (Crub) - e a Fundação Biblioteca Nacional, em novembro de 1993, conforme registra documento de

\footnotetext{
${ }^{3}$ Programa de Fomento à Extensão Universitária - 1994, do Ministério da Educação e do Desporto - Secretaria da Educação Superior (Sesu); Diretoria de Política do Ensino Superior (Depes); Comissão de Extensão Universitária.
} 
divulgação do Proler na Universidade do Estado Rio de Janeiro (UERJ): "com o objetivo de desenvolver ações conjuntas na implementação de planos e atividades voltados para a promoção do estímulo à leitura" (UERJ, s.d.). Um pouco depois, através de Ato Executivo da Reitoria de 31 de janeiro de 1994, é criado naquela universidade o Proler/UERJ. No mesmo ano, para sediar o Proler, é inaugurada a Casa de Leitura, localizada no bairro de Laranjeiras, no Rio de Janeiro, como um departamento da Biblioteca Nacional.

À criação do Proler, com proposta a atuar em âmbito nacional, segue-se imediatamente a proposta de um Programa de Extensão a ele vinculado na UERJ. Ressalte-se que a profa. Eliana Yunes, responsável pela criação do Proler/UERJ, que vinha coordenando, passou a exercer o cargo de Assessora Especial para a Política Nacional de Incentivo à Leitura.

O Proler/UERJ, vinculado ao Centro de Educação e Humanidades da UERJ, desenvolvia atividades de difusão da leitura a partir de textos literários e transcrições de lendas e fábulas, em diferentes ambientes e comunidades: associação de moradores no Morro dos Macacos, hospitais da rede pública municipal, enfermaria de adolescentes no Hospital Pedro Ernesto entre outros. As atividades desenvolviam-se com base na perspectiva de que o contato com a leitura deveria ser estabelecido em ambientes não convencionais, evitando os instrumentos acadêmicos, pois o prazer ligado à situação de convívio social favorecia a formação de leitores. Portanto, o mais importante nas atividades era descobrir os tipos de texto que poderiam interessar de imediato os leitores, capazes de ganhar sua atenção e provocar a identificação emocional. A perspectiva de que era necessário quebrar barreiras racionais para a recepção de textos literários dominava e acompanhava experiências como a realização de sessões de leitura acompanhadas da confecção de artesanato no Projeto Mãe Canguru, da Secretaria Municipal de Saúde do Rio de Janeiro até 2002.

O critério mais importante adotado na seleção do material para as leituras nos diferentes espaços era a capacidade de interessar os ouvintes ou participantes das reuniões promovidas pelos agentes de leitura categoria empregada no Proler, que abrangia todos e todas empenhados em atividades de difusão da leitura, como estudantes ou professores. $\mathrm{O}$ Programa de Leitura promovia também cursos que procuravam retomar as tradições, baseadas na oralidade, como a dos griots africanos ou dos contadores de histórias do meio rural brasileiro. Eram chamados de cursos de contação de histórias. Além disso, organizava os círculos de 
leitura semanais na biblioteca do Instituto de Letras, convidando os chamados leitores-guia, escritores ou professores, os quais davam início a uma sessão em que se propunha uma conversa informal sobre diferentes gêneros de textos. Os responsáveis pela organização das atividades do programa consideravam que as diferentes modalidades de leitura ou contato com o legado da cultura oral tradicional eram equivalentes em utilidade e importância, contribuindo para aquisição de um hábito de convívio com o conjunto das práticas leitoras.

A partir do início dos anos 2000, o programa passou a ser vinculado diretamente ao Instituto de Letras, com o nome de LerUERJ. A partir da contribuição crítica de docentes e estudantes, assim como pressionado pela diminuição das bolsas de extensão na universidade, o LerUERJ passou a priorizar atividades mais sistemáticas dirigidas a públicos-alvo como as crianças e os jovens moradores em comunidades de baixa renda próximas ao campus da universidade. Considerou-se, em sua organização, a necessidade de contribuir criticamente para repensar a eficácia das diferentes propostas e práticas relativas à promoção do livro e da leitura no país.

Algumas das propostas que nortearam o Proler retornaram como orientação para as políticas nacionais no setor, no Plano Nacional do Livro e da Leitura (PNLL). Este foi publicado inicialmente como Portaria Interministerial $\mathrm{n}^{\mathrm{o}} 1.442$, em 10 de agosto de 2006, tendo sido transformado pelo Decreto $\mathrm{n}^{\circ}$ 7.559, assinado pela presidenta Dilma Roussef em 2011. O PNLL englobou uma série de situações relacionadas ao livro, à leitura, à formação de público-leitor, às condições de produção e recepção da literatura. Alguns documentos e manifestações oficiais que cercaram sua elaboração mostravam-se de difícil concretização na prática, diante das condições que cercavam as atividades culturais no país, pressupondo, por exemplo, a existência de um número expressivo de cidadãos que tivessem superado o analfabetismo funcional. Entre essas, uma moção de um fórum de debates para a elaboração do Plano, a Câmara Setorial do Livro, Leitura e Literatura (CSLL), que preconizava: “A institucionalização do PNLL, como política pública de Estado, na forma de lei, garante a democratização do acesso ao livro; a criação e difusão da literatura; o fomento da produção e circulação da bibliodiversidade brasileira, com vistas à formação de uma nação de leitores" (MEC, s.d.).

A semelhança com propostas que nortearam o Proler revelou-se na iniciativa de expandir a experiência dos agentes de leitura, que teve 
grande repercussão na imprensa. O projeto Agentes de Leitura, criado em 2014 pelo Ministério da Cultura, mobilizava R\$ 30 milhões, baseavase na parceria com nove estados, 21 prefeituras e três consórcios municipais e previa atingir cerca de 450 mil pessoas nestas localidades. Propunha a concessão de 4.574 bolsas para jovens que moravam em comunidades carentes realizarem um programa de formação e atuarem em atividades semelhantes às desenvolvidas no Estado do Ceará em 2005, segundo matéria publicada na imprensa por ocasião do lançamento dessa experiência:

Cada jovem cadastra um grupo de até 25 famílias de sua comunidade, onde desenvolvem atividades de formação leitora, por meio de visitas domiciliares, empréstimos de livros, rodas de leitura, contação de histórias, criação de clubes de leitura e saraus literários abertos à população em geral. Eles trabalham de forma integrada com a Biblioteca Pública Municipal e com a escola da comunidade onde atuam (Mais..., 2010).

Uma diferença entre esse projeto e as atividades mais corriqueiras desenvolvidas no Proler era a proposta de conferir um caráter sistemático às atividades a serem realizadas pelos agentes de leitura. Mas incorria-se, ainda nesse caso, no problema apontado anteriormente: a discutível eficácia desse conjunto de atividades numa população com escolaridade deficiente, dificuldades de leitura, até mesmo com domínio muito limitado de convenções da escrita; e, além disso, o problema da formação daqueles e daquelas que se tornariam agentes de leitura. Isto porque, para a implementação do projeto, era previsto o recrutamento de estudantes com ensino médio completo - o que levanta a questão sobre a suficiência dessa formação escolar para o desempenho das atividades destinadas a eles, mesmo levando em conta o estágio de preparação previsto na implantação do projeto.

\section{Considerações finais}

Como procuramos demonstrar neste trabalho, persistem no Brasil problemas relativos à leitura, em especial à literária, que se devem às deficiências da escola, que ainda refletem a exclusão histórica do acesso à educação formal da maior parte dos indivíduos oriundos das classes populares ou um modelo deficiente da escola destinada a eles. Os projetos e programas de estímulo à leitura e de difusão da literatura são elaborados 
"apesar" dessas condições adversas. Como se observa no programa de formação de agentes de leitura, recursos vultuosos são empregados, a publicidade das medidas é grande, enquanto não se apresentam projetos que enfrentem com eficácia as condições estruturais que impedem o acesso de grandes massas da população ao livro e à literatura.

Nas últimas décadas, aumenta a importância das feiras literárias, que são apresentadas como um instrumento de divulgação do livro e transformam-se em eventos que certamente podem motivar o desejo de adquiri-lo estritamente na condição de mercadoria. A divulgação e a avaliação pela imprensa especializada em cultura sobre o sucesso desses eventos pauta-se, quase sempre, por critérios mercadológicos que ignoram a especificidade dos bens culturais.

A formulação de políticas culturais como as preconizadas pelo Proler, que repercutem nas propostas do PNLL, não leva em conta as condições do receptor que se almeja atingir, pressupondo-se a possibilidade de seduzi-lo, termo frequentemente utilizado em projetos e depoimentos sobre a difusão da leitura. O eventual contato com a leitura em voz alta de um texto, em especial quando é literário, é assumido como estímulo suficiente para despertar no leitor uma reação positiva, multiplicando o desejo de repetir essa experiência. Nesse sentido, parece relevante a reflexão de Perrotti, no estudo citado neste trabalho, sobre o caráter behaviorista de muitas experiências com a difusão da leitura e do livro no país. Pressupõe-se, por exemplo, que cercar a recepção da leitura de condições ambientais agradáveis pode condicionar o ouvinte ou leitor a buscar novamente essa experiência, até que se consolide um hábito.

Essas práticas, transformadas em procedimentos pedagógicos, podem se comprometer com projetos de inserção social acrítica voltados para comunidades de baixa renda. E observa-se que isso efetivamente acontece em trabalhos sociais que parecem se orientar por uma "pedagogia da submissão", conforme se pode observar em algumas iniciativas socioeducativas de ONGs no país, em contraste com a "pedagogia da libertação" preconizada por Paulo Freire. Ou seja, coloca-se a questão se o "hábito da leitura" serve para fornecer instrumentos para o autoconhecimento e a tomada de consciência sobre o lugar do sujeito numa dada sociedade e determinada época histórica, ou faz parte de uma "ocupação do tempo", que evita o comportamento agressivo ou rebelde nas classes populares e procura promover a inserção social de crianças e jovens, sem a preocupação de desenvolver 
a perspectiva crítica dos educandos ou estimular sua atuação transformadora do corpo social.

\section{Referências}

ALVITO, Marcos (2014). Apostila de história do Brasil República. 3. ed. Niterói: UFF. BOURDIEU, Pierre (2007). A distinção: crítica social do julgamento. São Paulo: Edusp; Porto Alegre: Zouk.

COELHO, João Batista (2009). Proler: um estudo sobe a sua implantação. Anais da Biblioteca Nacional, Rio de Janeiro, v. 129, p. 9-56.

CPDOC - CENTRO DE PESQUISA E DOCUMENTAÇÃO DE HISTÓRIA CONTEMPORÂNEA DO BRASIL (2015). Diretrizes do Estado Novo (1937-1945). Instituto Nacional do Livro. Rio de Janeiro: FGV. Disponível em: https://goo.gl/0rtez1. Acesso em: 9 nov. 2015.

FERRARO, Alceu; KREIDLOW, Daniel (2004). Analfabetismo no Brasil: configuração e gênese das desigualdades regionais. Revista Educação e Realidade, Porto Alegre, p.179-199, jul./dez.

MAIS 4,6 mil agentes de leitura (2010). Publishnews, São Paulo, 30 jun. Disponível em: https://goo.gl/XH793h. Acesso em: 5 nov. 2015.

MEC - MINISTÉRIO DA EDUCAÇÃO. Plano Nacional do Livro e Leitura PNLL. Histórico. Brasília, s.d. Disponível em: http://www.cultura.gov.br/pnll. Acesso em: 9 nov. 2015.

MELO, José Marques de (1999). Os meios de comunicação de massa e o hábito da leitura. In: BARZOTTO, Valdir Heitor (Org.). Estado de leitura. Campinas: Mercado de Letras, Associação de Leitura do Brasil, p. 61-94.

MOTA, Carlos Guilherme (1994). Ideologia da cultura brasileira, 1933-1974. 8. ed. São Paulo: Ática.

PEREIRA, Victor Hugo Adler (1998). A musa carrancuda: teatro e poder no Estado Novo. Rio de Janeiro: FGV.

PERROTTI, Edmir (1999). A leitura como fetiche. In: BARZOTO, Valdir Heitor (Org.). Estado de leitura. Campinas: Mercado de Letras, Associação de Leitura do Brasil, p. 125-148.

REIS, Fabio Pinto Gonçalves dos (2005). Cultura escrita e a escravidão brasileira: algumas práticas e seus significados no século XIX. In: CONGRESSO DE 
LEITURA NO BRASIL, 15., 5-8 jul. 2005, Campinas. Anais... Campinas: ALB. Disponível em: https://goo.gl/7xJQ7p. Acesso em: 9 nov. 2015.

SANTIAGO, Silviano (1982). Vale quanto pesa: ensaios sobre questões político culturais. Rio de Janeiro: Paz e Terra.

SOUZA, Ana Inês (Org.) (2001). Paulo Freire: vida e obra. São Paulo: Expressão Popular.

SOUZA, M. CECÍLIA C. C. de; HILSDORF, M. Lucia S. (2000). Oligarquias republicanas e a igreja ultramontana, um olhar para os esquecidos: José Vicente e a educação das meninas negras. In: CONGRESSO BRASILEIRO DE HISTÓRIA DA EDUCAÇÃO, 1., 6 a 9 de novembro, Rio de Janeiro. Anais... Rio de Janeiro: SBHE. Disponível em: https:/ / goo.gl/B2o7Z0. Acesso em: 9 nov. 2015.

TFOUNI, Leda Verdiani (1995). Letramento e alfabetização. São Paulo: Cortez.

UERJ - UNIVERSIDADE ESTADUAL DO RIO DE JANEIRO. Documento de divulgação do Programa Nacional de Incentivo à Leitura (Proler). Rio de Janeiro, s.d.

WANDERLEY, Sonia Maria de Almeida Ignatiuk (2008). Eu vi o Brasil na tevê: Estado e televisão nos anos 1950/60. In: ENCONTRO DE HISTÓRIA ANPUH RIO, 13., 4 a 7 ago. 2008, Rio de Janeiro. Anais... Rio de Janeiro: ANPUH-Rio. Disponível em: https://goo.gl/8Qh63Y. Acesso em: 9 nov. 2015.

Recebido em fevereiro de 2016.

Aprovado em agosto de 2016.

\section{resumo/abstract/resumen}

\section{Políticas públicas para a leitura e a literatura: o legado autoritário e a influência do mercado}

Victor Hugo Adler Pereira

Mirna Aragão de Medeiros

Apresentamos neste artigo as repercussões das dificuldades impostas por tradições autoritárias na organização da cultura e nos projetos educacionais do país para a ampliação do acesso ao livro e à literatura. Descrevemos e discutimos as principais iniciativas para diminuir os efeitos desse legado histórico traduzido nas políticas públicas no setor após o fim da ditadura militar, do Proler, nos anos 1980, até o PNLL, Programa Nacional do Livro e 
Leitura, implantado em 2011. Realizamos um paralelo entre essas iniciativas e a trajetória do Programa de Leitura da UERJ, que teve origem no Proler.

Palavras-chave: políticas públicas para a leitura e literatura no Brasil, Proler, Programa Nacional do Livro e Leitura, LerUERJ.

\section{Public policies for reading and literature: authoritarian legacy and influence of the market}

Victor Hugo Adler Pereira

Mirna Aragão de Medeiros

This essay examines how the legacy of authoritarian rule has impacted Brazil's educational and cultural projects, including access to books and other literary manifestations. The article describes and discusses the key initiatives in the public sector that were implemented to counteract this legacy. Among these is the Proler (a national program to promote reading) in the 1980's, and the PNLL - National Program for Books and Reading, that was launched in 2011. The essay establishes parallels between these two governmental programs and the track record of another program created to promote reading established at the UERJ (University of the State of Rio de Janeiro), which originated in Proler.

Keywords: public policies for reading and literature in Brazil, Proler, National Program for Books and Reading, LerUERJ.

\section{Políticas públicas para la lectura y la literatura: el legado autoritário y la influencia del mercado}

Victor Hugo Adler Pereira

Mirna Aragão de Medeiros

En este documento presentamos las repercusiones de las dificultades impuestas por las tradiciones autoritarias a la organización de proyectos culturales y educativos en Brasil encaminados a ampliar el acceso a los libros y la literatura. Describimos y analizamos las principales iniciativas para reducir los efectos de este legado histórico, traducidas en políticas públicas en el sector al fin de la dictadura militar: el Proler, en la década de 1980; y el PNLL, Programa Nacional del Libro y la Lectura, en 2011. Realizamos un paralelo entre éstos y la trayectoria de Programa de Lectura de UERJ (Universidad del Estado de Rio de Janeiro) que se originó en Proler.

Palabras clave: políticas públicas para la lectura y la literatura en Brasil, Proler, PNLL, LerUERJ. 